\title{
UK theses and the British Library EThOS service: from supply on demand to repository linking
}

Sara Gould, Development Manager for Researcher Services at the British Library.

\section{Abstract}

This paper aims to describe the transition of EThOS, the British Library's E-Theses Online service, from its original role as a transactional document supply service to the service seen today where it forms part of the UK's network of institutional repositories, open access and still-developing research funder mandates. The constituent parts of the EThOS service are described, and an analysis is given of the development of open access repositories, electronic theses and the way that PhD theses have become an important resource for cutting-edge research content for researchers worldwide. The value of doctoral theses for researchers continues to grow and be recognised. Many UK institutions have moved to mandatory open deposit of electronic theses, and many are digitising their older print thesis collections. Public funders are starting to track open deposit of the theses they fund; and research organisations are analysing the full UK metadata collection to understand trends in PhD research areas.

\section{$\underline{\text { Introduction }}$}

Until a few years ago, one strand of the British Library's Document Supply Service was the British Thesis Service. This service offered an interlibrary loan and supply service for UK doctoral theses.

In operation for several decades, universities across the UK would send copies of their theses to the British Library at Boston Spa; the document supply service would make a microfilm or microfiche copy and then return the original thesis to the awarding university. The surrogate copy formed the thesis loan collection, and the British Library would lend the fiche - or supply a copy - in response to document supply requests.

Legal Deposit legislation in the UK ${ }^{1}$ requires publishers to deposit a copy of every UK publication with the British Library for archival purposes. Doctoral theses are not covered by this Legal Deposit law, and there is no national mandate for thesis deposit. Each Higher Education institution (HEI) develops its own policy for students submitting their theses, and for making them available to other researchers. These access options can include free open access direct from institutional repositories, interlibrary loan, scanned copies supplied in direct response to a request, or a requirement for researchers to visit the library of the awarding institution in person to view the print copy held in the library's store.

The British Library's thesis collection (consisting of microfilm surrogates) was the closest thing the UK had to a national thesis collection; print theses have never been collected by the British Library.

In 2009, the EThOS electronic thesis service ${ }^{2}$ was launched: a digitisation and supply service that entirely replicated the British Thesis Service, only in e- rather than print:

- Institutions continued to send their theses in response to requests

- Microfilming was replaced by scanning

- The 'supply' of a microfiche copy was replaced by the ability for the researcher to download the item direct from EThOS.

\footnotetext{
${ }^{1}$ http://www.bl.uk/aboutus/legaldeposit/introduction/

2 http://ethos.bl.uk
} 
While the format of the copies had changed, the core idea remained: the British Thesis collection (now digitised) held by the British Library document supply service was the one stop shop for UK theses. They could be ordered by other libraries or users, and the Library would 'supply' them by making surrogate copies available from a single source, often referred to in early EThOS communications as the "central hub".

Usage of UK doctoral theses for research purposes has been growing ever since, and EThOS is now a permanent British Library service that continues to support UK Higher Education by making the doctoral research outputs of all UK universities widely available through a single point of access.

In recent years, the value of doctoral theses as an important source of research content has been increasingly recognised [Gould, 2013], access to UK doctoral theses has been transformed, and EThOS has evolved from a transactional document supply service, to become just one player in a network of institutional repositories, open access and still-developing research funder mandates. This transition from print to digital, from transactional requesting to aggregated resource sharing, from 'supply' to 'access', is the subject of this paper.

\section{EThOS today}

EThOS is a free web-based resource, for use by anyone from anywhere in the world. Its aims are to:

- Help increase the visibility of the UK's doctoral research

- Make doctoral theses more accessible for researchers

- Provide the national record of UK doctoral theses

- Provide full access to the full text of as many UK theses as possible.

By August 2015, there were 410,000 records in the EThOS database, and around 170,000 full theses were instantly accessible for download. Of the remainder, around three quarters (some 180,000) are available to be digitised from paper originals in response to orders from requesting users.

\section{Key EThOS Statistics}

- The database has 410,000 records, and provides immediate access to 170,000 full-text theses

- That's 56 million pages of unpublished doctoral research content

- 4000 new records and 2500 accessible theses are added each month

- 38,000 full theses are accessed via EThOS each month

- $45 \%$ users are from UK, then US (10\%). India, Germany, Malaysia, Canada, China, Australia are all active users (2-3\% each)

- $43 \%$ users are postgraduate students, then academic staff (12\%), undergraduates ( $9 \%)$, librarian (8\%)

- 400 print theses are digitised each month through EThOS digitisation on demand. 
EThOS now has a record for around $87 \%$ of 'recent' ${ }^{3}$ theses awarded by UK institutions, and the aim is to achieve a $100 \%$ comprehensive record if possible. The gaps are gradually being filled by converting HE library catalogue records to EThOS repository records, but some gaps will persist because of embargoes. Many theses today are deposited with often lengthy embargoes, and some institutions do not create bibliographic records for such theses. If there is no institutional record, an EThOS record cannot be created and the thesis will remain unlisted until the embargo is lifted, in some cases up to five years later.

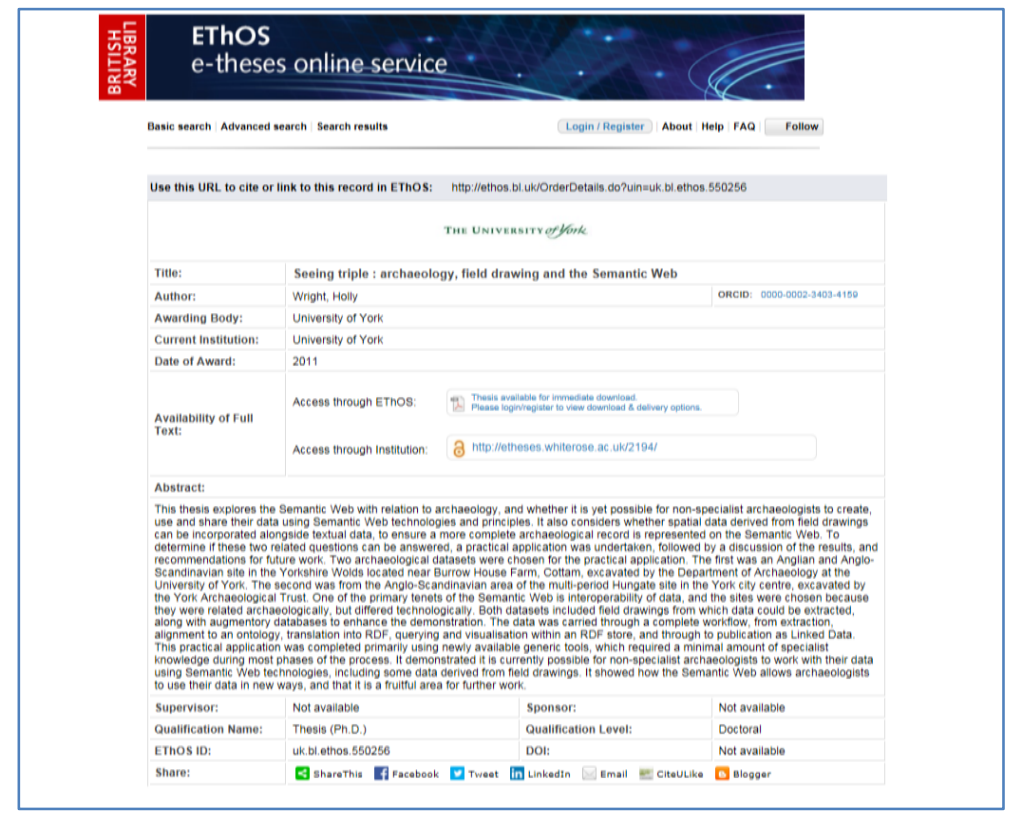

Figure 1: a typical EThOS record

\section{Adding content to EThOS}

Following a change of business model in 2013, EThOS is now managed and delivered by the British Library in close co-operation with UK Higher Education (HE). A Memorandum of Understanding (MOU) has been signed between the British Library and each participating institution. As well as setting out our shared aim to open up access to UK theses to support researchers everywhere, the MOU also defines the way in which each institution wishes the BL to ingest and hold its records and/or full theses in EThOS.

At the start of EThOS there was just one way to get the content into the database: print theses were sent by institutions, EThOS records were created from scratch, the thesis was copied and uploaded into EThOS, and the original returned.

Today, this process still takes place - for just the $1 \%$ of requested theses which need to be digitised before being made available for download (digitisation on demand is discussed later in this paper). Unsurprisingly, the vast majority of new records being added to EThOS now arrive as a result of a direct harvest of thesis metadata from institutional repositories or by uploading a batch of records

\footnotetext{
${ }^{3}$ According to data provided by the Higher Education Statistics Agency (HESA), 309,000 doctoral degrees were awarded in the 20 years 1995 - 2014. EThOS holds records for 268,000 of these, or $87 \%$.
} 
provided by the academic library itself - see Fig 2 below. By August 2015, the EThOS Metadata Manager was harvesting thesis metadata on a monthly basis from 111 institutional repositories out of approximately 135 institutions which award doctoral degrees in the UK.

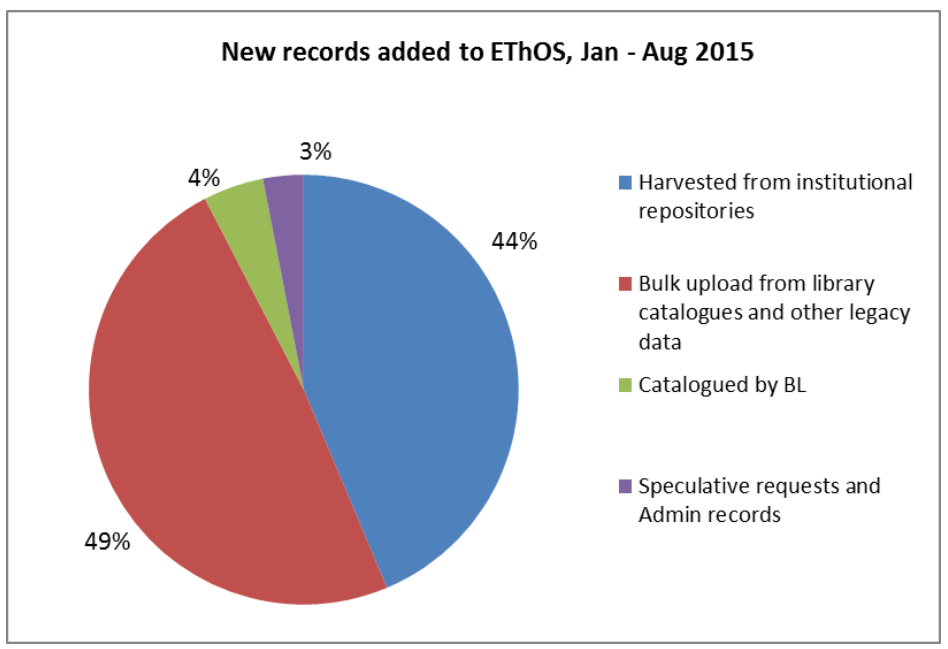

Figure 2: Source of the 32,500 new records added to EThOS during Jan to Aug 2015

As well as the bulk ingest of legacy catalogue records, the British Library also catalogues from scratch theses which do not have a digital record. A declining number of institutions do not yet have an institutional repository or do not require students to deposit their thesis into the repository, or have not yet made the transition to electronic theses - see Fig 3 below. For institutions that still handle only print theses, the British Library will produce EThOS records from scratch, although efforts are now being made to reduce time spent in this very resource-intensive added value service.

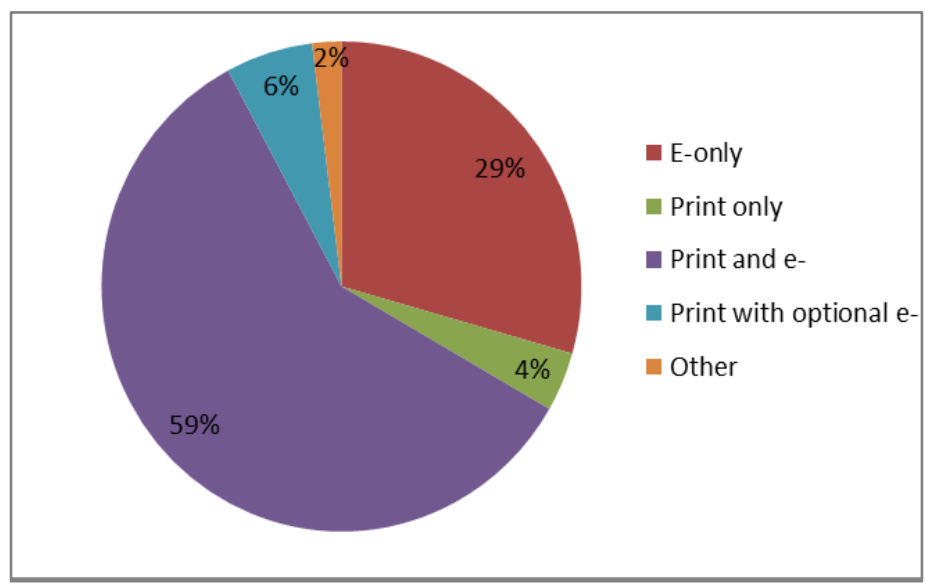

Figure 3: Students' thesis submission requirements, by institution [Gould, 2015]

The aggregated data is further enhanced before being added to EThOS as part of the management of the national record. Recent theses are likely to be first recorded (and held) in the institutional repository, whose bibliographic records are sometimes created by the students themselves on deposit of their thesis. EThOS spends time to ensure that records harvested into EThOS, created by 
British Library cataloguers or converted from institutional catalogue records are not duplicated and are accurate.

There is also unlimited potential to enrich the metadata to improve discoverability and re-use. Because they have never really been recognised as formal publications, theses do not have a persistent identification scheme as the ISBN or ISSN. In the digital world, persistent object identifiers are important:

- They are a match key for multiple versions of the same work

- Reduce duplication of records

- Makes for easier citation of the item and avoids link rot

- They are needed to support linking of separate parts of the same work, for example, supplementary files to the main thesis work.

A recent project has investigated how persistent Digital Object Identifiers ${ }^{4}$ (DOI) could be allocated to doctoral theses to bring about the benefits listed above. The Unlocking Thesis Data project [Grace, 2015] surveyed current application of DOls for theses and looked at the challenges and possible first steps to initiating widespread take-up. At the time of writing, no UK institution had yet begun to assign DOIs to their theses but many were on the verge of doing so. Just three UK thesis records currently have a $\mathrm{DOI}^{5}$, having been assigned as proof of concept exemplars as part of the project.

The uptake of ORCiD author identifiers ${ }^{6}$ by doctoral students is also taking hold, encouraged by institutional progress in ORCID implementation. PhD theses are often the first formal scholarly output produced by early researchers so it makes sense to register for a personal ORCiD profile as early as possible in a researcher's career. As with thesis DOls, the Unlocking Thesis Data project concluded that although many students now have ORCiDs, no UK HE institution was yet making ORCiD identifiers available in their harvestable thesis metadata. Again, a small number of ORCiDs have been added to EThOS records to demonstrate the concept ${ }^{7}$.

Furthermore, the comprehensive data set has value for other aggregators and resource discovery services $^{8}$, as well as specialist indexes and specific projects. EThOS data - complete with links direct to the institution-held theses where available - is indexed by Google Scholar, Ebsco Discovery ${ }^{9}$, OpenGrey ${ }^{10}$, Primo Central ${ }^{11}$, as well as the British Library's own catalogue ${ }^{12}$ and the nearest thing we have to an international index of theses, NDLTD's Global ETD Search ${ }^{13}$.

\footnotetext{
${ }^{4}$ https://www.doi.org/

${ }^{5}$ These are EThOS IDs $\underline{650368}, \underline{640751}$ and $\underline{630167}$, awarded by the Universities of Glasgow, Southampton and East London respectively.

${ }^{6}$ http://orcid.org/

7 For example see EThOS IDs 594151, 511031 and $\underline{550256}$

${ }^{8}$ EThOS metadata is available for harvesting for non-commercial re-use. The OAI-PMH source URL is http://simba.cs.uct.ac.za/ ethos/cgi-bin/OAl-XMLFile-2.21/XMLFile/ethos/oai.pl

${ }^{9}$ https://www.ebscohost.com/discovery/about

${ }^{10}$ http://www.opengrey.eu/

${ }^{11} \mathrm{http}: / /$ www.exlibrisgroup.com/category/PrimoOverview

${ }^{12}$ Explore the British Library http://explore.bl.uk/primo library/libweb/action/search.do?vid=BLVU1

${ }^{13}$ http://search.ndltd.org/
} 
Nevertheless, the Pro-Vice Chancellor for Research at one research-intensive institution recently described PhD theses as "dramatically underused", adding that their "sheer potential for research" had yet to be realised [Schurer, 2014].

\section{The open context}

In the mere six years since EThOS was launched the scholarly communication world has been overturned by the emergence of Open Access. In 2012, the so-called Finch Report ${ }^{14}$ recommended $^{2}$ that the outputs of research funded by the public purse should be made more widely available for more people to access, with the aim of speeding up some parts of the research process and demonstrating more strongly the benefits of public funding of research.

One result of the Finch Report was the UK Research Councils' policy on Open Access ${ }^{15}$ which now required researchers to publish their results in an Open Access journal via either the so-called gold or green route. In 2013 HEFCE, the Higher Education Funding Council for England published its guidance $^{16}$ for the next and subsequent REF allocation of Higher Education funding. The guidance made it clear that all research outputs which institutions intended to submit for the REF post-2014 would need to be deposited from 2016 onwards in an open access repository.

Both of these policies relate only (for now at least) to journal articles and conference papers. So far, $\mathrm{PhD}^{17}$ theses are not the subject of a formal Government Open Access policy. However theses are increasingly considered a valid research output in their own right and the first moves towards a future mandate for RCUK-funded PhDs are now emerging. Indeed, from academic year 2015/16 PhD students will be required to report the scholarly outputs of their doctoral research to the outcomes reporting system already used to track academic research articles and conference proceedings produced in the course of research funded by RCUK. For the first time, RCUK-funded PhD students will have to record details of their written articles, conference papers - and in due course their doctoral thesis ${ }^{18}$. This could turn out to require major changes to the management of theses in institutions, although sanctions are unlikely to be applied to students failing to report their outputs for the first few years while the process is embedded.

In the meantime, postgraduate research training supported by the Research Councils or RCUK is governed by the RCUK Terms and Conditions for Postgraduate Research Training Grants ${ }^{19}$ which include the expectation that theses will be deposited in an open access repository.

Alongside these open access developments, institutions themselves increasingly want to raise the profile of their expert research - including visibility of the research itself, the excellence of individual

\footnotetext{
${ }^{14} \mathrm{https}: / /$ www.gov.uk/government/news/government-to-open-up-publicly-funded-research

${ }^{15}$ http://www.rcuk.ac.uk/research/openaccess/

${ }^{16} \mathrm{http}: / /$ www.hefce.ac.uk/rsrch/oa/

${ }^{17}$ The term PhD thesis has been used in this article to refer to all doctoral theses regardless of the specific qualification name of the degree. While the vast majority of theses in EThOS are PhD theses, there are also hundreds of records for D.Phil, D.Litt, M.D. etc

${ }^{18} \mathrm{http}: / /$ www.rcuk.ac.uk/research/researchoutcomes/compliance/

${ }^{19}$ Terms and Conditions of Research Council Training Grants, RCUK, 2014. http://www.rcuk.ac.uk/skills/training/
} 
academic departments and indeed the whole university. Openly accessible theses offer a window on the incredible postgraduate research being carried out in the UK and services like EThOS aim to support and increase the visibility of that research in the global competition to attract the best research students.

So institutional repositories have flourished in the UK and theses are one of the biggest content types found in those repositories [Lambert, 2015]. And all the time, EThOS has grown, become more robust, more trusted and more comprehensive.

Usage of EThOS: individual theses and the aggregated corpus of records

i. Individual theses

The key performance indicator for EThOS is described as the number of full theses accessed by researchers via EThOS - see Fig 4 below. In 2015 to August, this figure averaged 40,000 theses a month, or some 12 million pages of cutting edge, often unique research content.

There are three ways a user can access the content listed in EThOS. When EThOS was launched the only route to the full theses was via download direct from the EThOS database. This still accounts for $35 \%$ of all theses viewed, or some 81,000 over the first six months of 2015 . But the emergence of institutional repositories, open access developments and of course the transition from print to electronic for vast swathes of research material including theses means that users now also have the option of following links in the EThOS record to the institution-held copy of the thesis. Today, users access $64 \%$ of all theses discovered in EThOS by following links to the repository copies and this proportion is growing as more institutions introduce mandatory open deposit of newly awarded theses, institutional repositories reach maturity, and EThOS harvesting becomes increasingly effective.

The third option for users to access a full thesis which does not yet exist in digital form is to order a scanned copy through the EThOS digitisation on demand service. Digitisation orders now count for around $1 \%$ of all traffic - see Fig XX below.

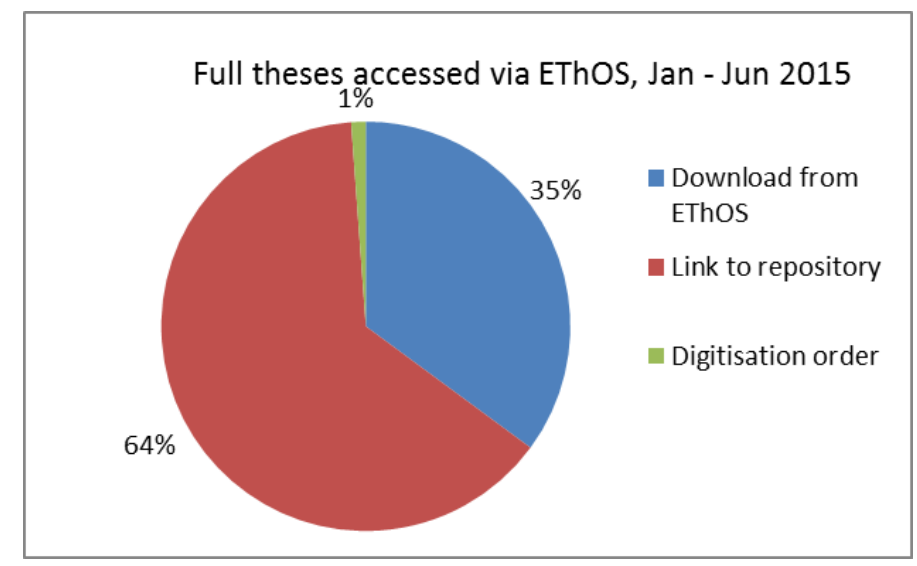

Figure 4: Number of full theses accessed via EThOS, Jan - June 2015; showing the proportion accessed via three different routes. 
In 2013, an EThOS user survey [Gould, 2013] gathered information on how researchers use both theses and EThOS for their research. The survey found that while three quarters of them used EThOS as expected to access the research content of the theses themselves, a quarter used EThOS to find information about the PhD research process, research methodologies or how to structure their own thesis. This ability for users to be able to browse information from all UK institutions at the same time allows them to see a picture of UK doctoral research as a whole and pick up trends and information about emerging research fields, new subject areas, thesis structure and research methodologies, as well as being able to draw out references and research content from across all UK theses from one place. Comments from respondents included:

"I look at Ethos regularly to find out if a thesis has been written on a particular subject or topic."

"To get used to the size of argument or issue required at doctoral level."

"Helped me with structuring my thesis."

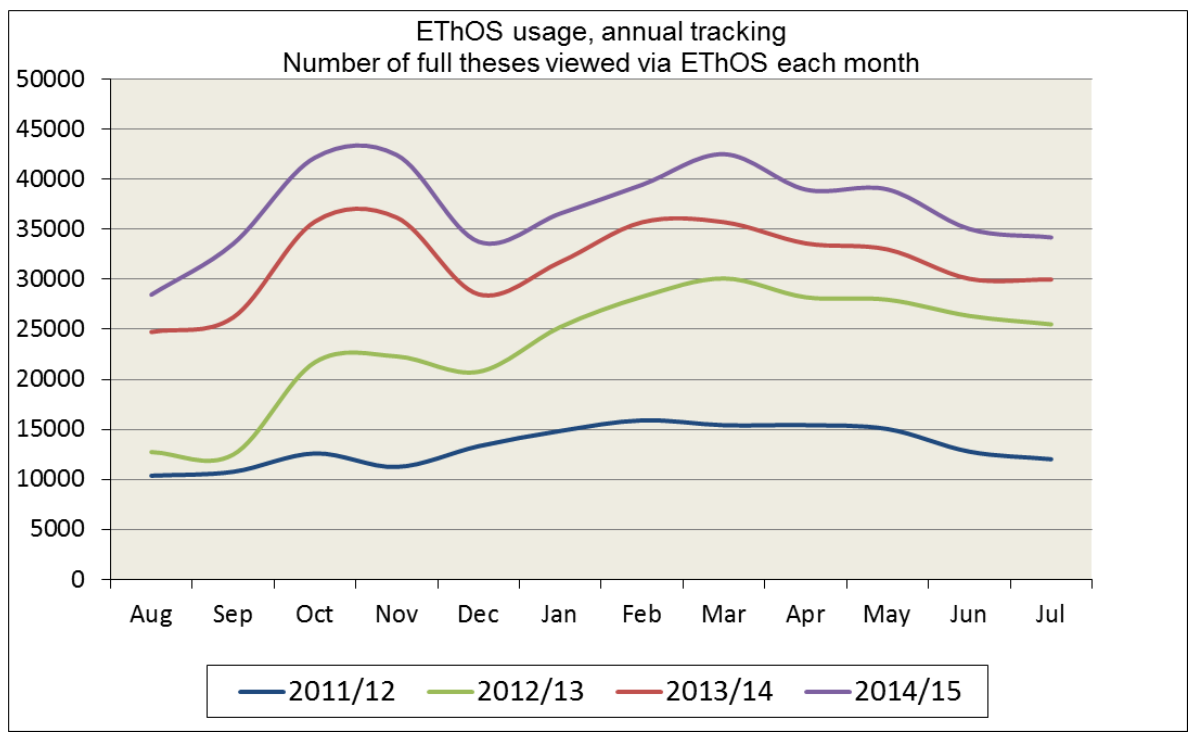

Figure 5: Number of full theses accessed via EThOS per month showing annual trend since 2011.

ii. Using the aggregated dataset

Beyond the use of EThOS by individual researchers seeking access to individual thesis titles to support their own research, the aggregation of the UK's thesis records into a single set of highquality, de-duplicated and enhanced metadata offers other benefits that add value in the management of the thesis corpus as a whole; with the data available to analyse, for example, trends in research patterns over time in particular subjects, or the spread of postgraduate opportunities among a subset of institutions.

Three case studies illustrate the value of this data:

Case study 1: Dementia research workforce pipeline 
The Alzheimer's Society appointed RAND Europe to produce a report on the state of dementia research in the UK. RAND wished to investigate the dementia workforce pipeline - how many researchers are working on dementia and how this is changing over time. As EThOS contains records for a high proportion of recent PhD theses, RAND contacted the EThOS team to ask for their help with this investigation. The Library's metadata experts undertook bespoke analysis for RAND and produced a list of theses awarded from 1970 onwards.

RAND were able to conclude that dementia-related $\mathrm{PhD}$ research has been steadily increasing over the last 30 years. However, cancer-related PhDs have skyrocketed over the same time frame. Now five times more PhD researchers chose to work on cancer than dementia

RAND were also interested in what proportion of $\mathrm{PhD}$ students studying dementia stay in the field. To investigate this they traced about 1500 dementia $\mathrm{PhD}$ researchers to find out about their career since finishing their PhD. The results show that of those who do complete a PhD in dementia, retention in the field is poor with $70 \%$ leaving the field within four years. Only $21 \%$ are still researching dementia [Howe, 2015]

Case study 2: Trends in chemistry research

The British Library provided 30,000 thesis records in the field of chemistry to the Royal Society of Chemistry, with comprehensive metadata including year of award, institution, keyword, abstracts and Dewey subject classification. Royal Society of Chemistry used the data to analyse trends in chemistry research - and by implication trends in the focus of chemistry research funding as well.

Projects such as this illustrate the importance of making abstracts available as part of the metadata to allow far more accurate analysis than would be possible using titles alone. And the professional addition of subject headings such as Dewey is essential if subject-specific subsets of the data are to be provided for such projects. 
Case study 3: A novel use of the specialist language found in PhD theses

FLAX Language Learning (http://flax.nzdl.org/greenstone3/flax)

The University of Waikato and Queen Mary University Language Centre have a project called FLAX Language Learning, which is building a language learning database for non-English speaking Law students. Law students enrolled on specific language courses at pilot universities can use the language learning online resources to develop students' ability to produce appropriate English language written material.

The project has used abstracts from the EThOS database to extract common sentence structures, key phrases and text strings populate the FLAX tools and build language learning games and exercises.

The project considers that UK theses represent a corpus of model student writing combined with very specific and specialist language, making them an excellent source of raw material with which to populate the learning corpus.

\section{$\underline{\text { Thesis digitisation }}$}

Of all the parts of the EThOS service, the digitisation of print theses continues to provide a unique feature to EThOS, allowing it to bring together new e-born theses and older print theses into a single online database. Digitisation was the original backbone of EThOS, indeed around 25,000 theses were digitised in order to build a critical mass of content before its launch thanks to considerable Jisc ${ }^{20}$ funding and the contribution of a key group of early-adopting institutions. Digitisation on demand remains well used today, averaging 430 orders a month in 2015:

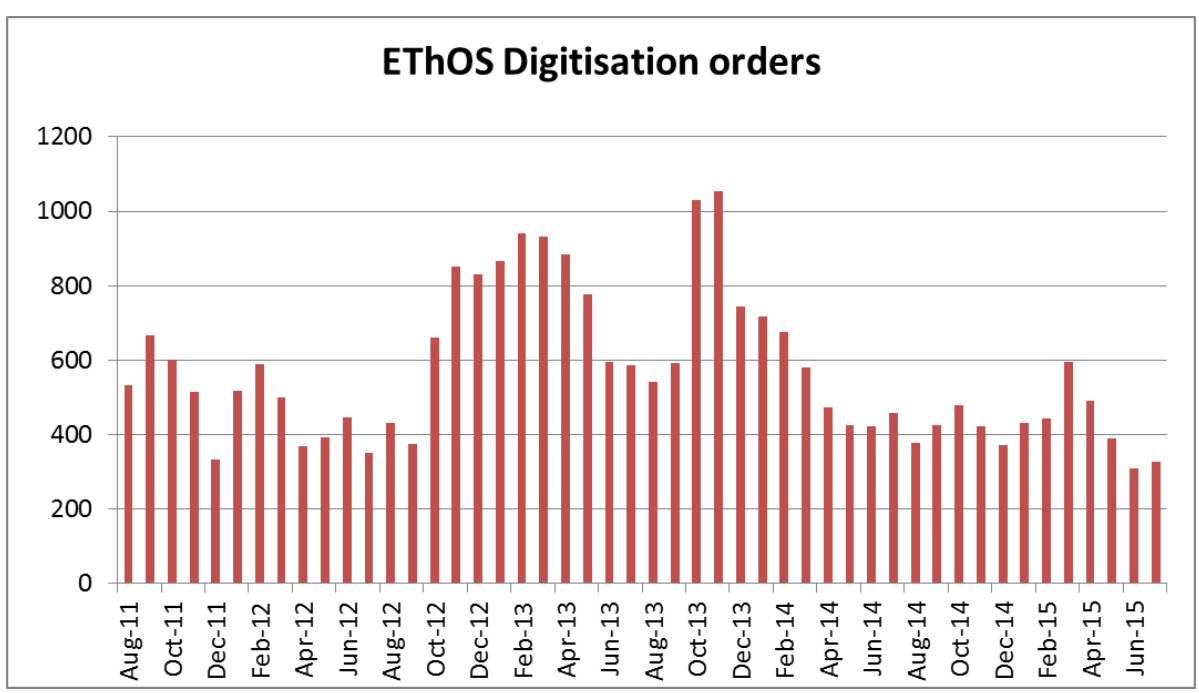

Figure 6: EThOS digitisation orders per month, since August 2011.

${ }^{20}$ www.jisc.ac.uk 
It may seem surprising that so many theses are still being requested for digitisation in these days of electronic-everything, but the consistent demand can be explained by the gradual growth in overall usage of EThOS. While digitisation orders remain roughly constant, they now represent just less than $1 \%$ of overall traffic as shown at Figure 6 above.

The research value of older theses is illustrated not just by EThOS digitisation on demand traffic but also by the plethora of digitisation projects being undertaken in UK universities. For example, earlier this year Keele University used the British Library's Imaging Services to digitise large numbers of its older theses in a project which both opens up the content to researchers worldwide and eliminate inefficient handling of user requests to view individual theses in print.

In another initiative, Proquest has been working with a number of institutions to digitise thousands of their theses under a project arrangement which delivers benefits to the institution, Proquest's own services and users of the thesis content since the digitised theses eventually become openly accessible via the institutional repositories (Boylan, 2015).

Digitisation on demand is the part of EThOS that now most closely represents a document supply service, with users discovering the existence of a thesis but no immediate availability of the full item. It is also the only part of EThOS for which a payment is required: someone has to pay the cost of the scanning service! On discovering a required thesis, the user will meet one of two possibilities: either the holding institution will pay for the cost of digitisation, or the cost is passed on to the end-user. The holding institution can choose whether to allocate budget to support the digitisation of its print theses - a neat way to ensure a steady stream of the most popular theses are digitised; or if thesis digitisation is not something the institution can support, the user is required to cover the digitisation fee through credit card payment. A third option is also available whereby institutions can choose not to have their print theses made available for digitisation on demand through EThOS - see Fig 7 below.

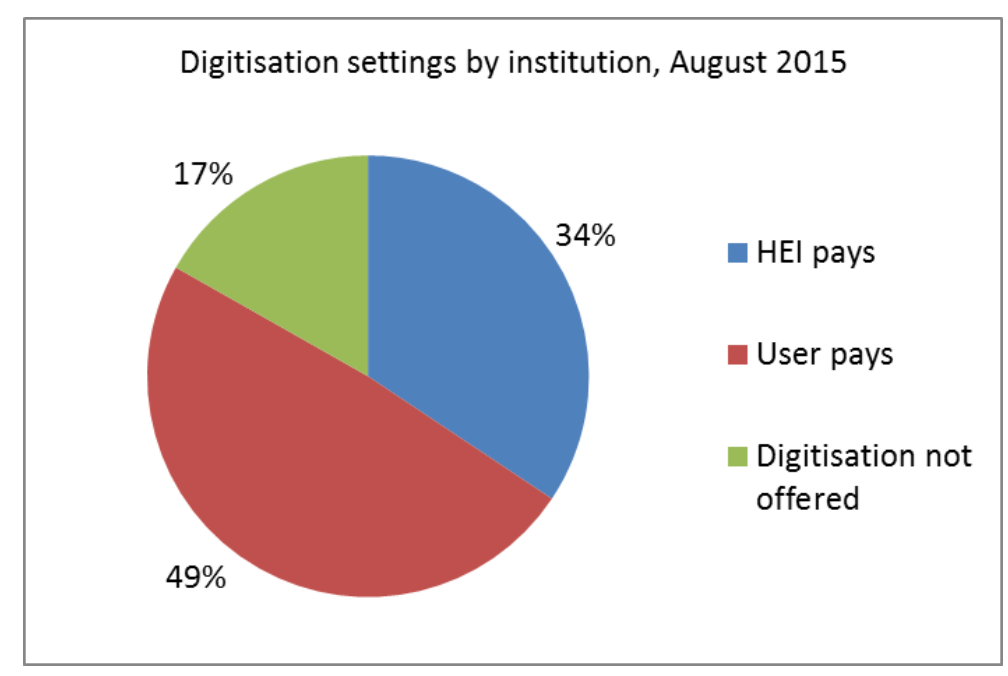

Figure 7: Digitisation settings selected by participating institutions, at August 2015.

Figure 7 shows that only one third of all institutions now have a budget set aside to cover the scan costs of their own theses. But perhaps inevitably, the number of orders for theses from these institutions is much greater than for theses whose scan costs must be paid by the user. But even the f54.48 scan fee can turn out to be good value if the alternatives are a personal visit to a remote 
library to view the print copy, or an interlibrary loan, or worst, no online access to the full thesis at all.

\section{Looking forward}

The launch of EThOS in 2009 was the culmination of years of hard work and commitment by a small project team to a belief that opening up access to doctoral theses would be a good thing for individual researchers, the authors of the theses themselves and for participating institutions. The EThOSNet project [Russell, 2006], supported extensively by Jisc funding and vision, worked hard to persuade the community that the move to electronic theses was inevitable and would bring extensive benefits.

They were right. Six years on print theses are becoming passé, Open Access has taken hold, and advocates cannot imagine the dark days when a single copy of a thesis was hidden away on a quiet library shelf and consulted by just a handful of readers. Today's theses are downloaded hundreds of times - even thousands of times if a news story takes hold ${ }^{21}$.

The British Library is now exploring what the future direction should be for EThOS. New challenges are emerging such as the complexity of many of today's practice-based or complex multimedia theses, PhD by publication and the need to balance open thesis deposit with expectations of future publication opportunities based on the doctoral research. The question of e-thesis preservation also has not yet been investigated in any depth, and we will watch out for further Open Access developments for PhD students with interest.

The results of our market research and discussions with the HE community will be known in early 2016, so watch out for further exciting developments in the world of theses.

\section{Bibliography}

Boylan, C. (2015) "Enhancing the visibility and impact of electronic theses and dissertations", presented at the UKSG Conference 2015. Podcast (accessed 12 October 2015) https://www.youtube.com/watch?v=TqRHJq4DEjw\&feature=youtu.be

Clement, G (2013). "American ETD dissemination in the age of open access: ProQuest, NoQuest, or allowing student choice", College \& Research Libraries News, vol. 74 no. 11, p562-566.

\footnotetext{
${ }^{21}$ Such as the case of EThOS ID 632704 which won its author the US Academy of Management's Heizer Entrepreneurship Award for the Best Doctoral Thesis. The thesis has been downloaded more than 3000 times, probably because the award presenter called it "the best PhD thesis in the world"! http://www.msn.com/ptpt/financas/carreira-e-educacao/portugu\%C3\%AAs-escreveu-melhor-tese-de-doutoramento-do-mundo/arBBIGjGR?ocid=mailsignoutmd
} 
Gould, S (2013) "EThOS user survey, July 2013", available at

http://www.bl.uk/reshelp/findhelprestype/theses/ethos/ethos-user-survey-july2013.pdf (accessed 3 October 2015)

Gould, S. et al (2015) "Unlocking Thesis Data: Phase 1 survey of UK Higher Education Institutions". University of East London. DOI 10.15123/PUB.4274

Grace, S. et al (2015) "Mapping the UK thesis landscape: Phase 1 project report for Unlocking Thesis Data" Project Report. University of East London, London. DOI 10.15123/PUB.4307

Haddaway, N (2015) "The role of Google Scholar in evidence reviews and its applicability to Grey Literature searching", PLOS One, 17 September 2015, Available at http://journals.plos.org/plosone/article?id=10.1371/journal.pone.0138237 DOI: 10.1371/journal.pone.0138237 (accessed October 21 2015).

Howe, K. (2015) "A novel use of PhD data: Investigating the state of the Dementia Workforce". British Library Science blog http://britishlibrary.typepad.co.uk/science/2015/09/a-novel-use-of-phddata.html\#sthash.DguRy3JL.dpuf (accessed 13 October 2015)

Lambert, J. (2015) "'How much?": Aggregating usage data from Repositories in the UK", 10th International Conference on Open Repositories, Indianapolis, 10 June 2015. Available at http://www.irus.mimas.ac.uk/news/IRUS-UKatOR2015.pdf (accessed 12 August 2015)

Moyle, M. et al (2012) "Electronic doctoral theses in the UK: a sector-wide survey into policies, practice and barriers to Open Access", UK Council for Graduate Education. Available at http://discovery.ucl.ac.uk/1339905/ (accessed 3 October 2015)

Russell, J. (2006) "EThOS: progress towards an electronic thesis service for the UK". Serials: The Journal for the Serials Community, 19 (1). pp. 32-36. ISSN 1475-3308 Available at http://epapers.bham.ac.uk/629/ (accessed October 21 2015)

Schurer, K. (2014) "ETD keynote on open access". Presented at the International Conference on ETheses and Dissertations, 23-26 July 2014, Leicester. Available at https://www.youtube.com/watch?v=yh7mTKei6Kk (accessed 21 October 2015) 